\title{
Effect of Different Fuels (Methane, Methanol, and Hydrogen) on Rotary Engine Operation
}

\author{
Jai-Houng Leu, ${ }^{1}$ Tian-Syung Lan, ${ }^{2}$ Ay Su, ${ }^{3}$ Lie-Ping Zhang, ${ }^{2}$ and Xuan-Jun Dai ${ }^{2 *}$ \\ ${ }^{1}$ Shandong Polytechnic, No. 23000, Jin Ten East Road, Jinan City, Shandong Province 250353, China \\ ${ }^{2}$ College of Mechanical and Control Engineering, Guilin University of Technology, Guilin, Guangxi 541004, China \\ ${ }^{3}$ Department of Mechanical Engineering, Yuan Ze University, Taoyuan City 32003, Taiwan
}

(Received July 20, 2020; accepted December 9, 2020)

Keywords: rotary engine, power, torque, methane, methanol, hydrogen

Three different fuels, methane, methanol, and hydrogen, were tested to investigate their effects on the operation of a rotary engine by measuring the output power, torque, and exhaust air temperature. The results showed that the output power with methanol was lower than those with methane and hydrogen at the same engine speed. Methanol enabled the engine to have the widest operation range from 5000 to 18000 revolutions per minute (RPM). The engine using hydrogen and methane operated stably in the ranges of 6000 to 10000 RPM and 7000 to 14000 RPM, respectively. Methanol had greater efficiency than hydrogen and methane, and hydrogen had higher output power and torque than methane and methanol. To use methanol for a rotary engine, a higher-pressure pump is required, and a mixture of liquid and gas fuels enables better operation than the use of methane or hydrogen.

\section{Introduction}

A rotary engine has a lower compression ratio than a piston engine despite its higher power, smaller size, higher rotation speed, and lower vibration than those of a piston engine. The low compression ratio causes low efficiency, incomplete combustion, and pollutant emission, especially when using liquid fuels, which hinder the use of the rotary engine in more vehicles. Therefore, there has been research on the use of different fuels for a rotary engine to solve these problems and improve its overall performance.

To enable the combustion of different fuels in a rotary engine, investigation is needed on the refueling process, the mixing ratio of fuel and air via fuel injection control, the ignition time, the lubrication of the combustion chamber, and so on. Zhenzhong et al. studied an in-cylinder injection-type engine using hydrogen as the fuel and suggested the injection of hydrogen into the cylinders at the post-compression stroke. ${ }^{(1)}$ Hydrogen was tested in their study as it has the highest heating value among the gas fuels and because the electrochemical reaction during the combustion process does not emit a significant amount of air pollutants. Hydrogen fuel engines are generally regarded as having a higher combustion rate and energy efficiency than

*Corresponding author: e-mail: daixuanjun@163.com https://doi.org/10.18494/SAM.2021.3033 
engines using other fuels. The hydrogen fuel engine in Ref. 1 used a fuzzy ignition controller that optimized the amount of hydrogen for ignition. As a result, the performance of the engine was optimized for stable operation. Sopena et al. modified a 1.4-liter gasoline engine to use hydrogen. The engine had an excess air coefficient of less than 2.5 and a maximum speed of 4000 revolutions per minute (RPM). They proved that the thermal efficiency of their hydrogen engine was significantly higher than that of the gasoline engine. ${ }^{(2)}$ Toward the effective use of hydrogen fuel, compressed natural gas (CNG) has been studied as it has intake conditions similar to those for hydrogen. CNG can replace methanol in a rotary engine with an adjusted optimal ignition time and mixing ratio. Park et al. ${ }^{(3)}$ examined whether hydrogen-compressed natural gas $(\mathrm{HCNG})$ reduced pollutant emission. They found that an HCNG engine had higher thermal efficiency and less emission than natural gas engines and suggested that the number of cylinders affected the engine operation when using HCNG because of differences in fuel mixtures and the excess air coefficient. Park et al. ${ }^{(4)}$ investigated the relationship between a high compression ratio and the performance of an HCNG engine. They tested an HCNG engine with a wide-open throttle (WOT) and demonstrated its high charging capacity with a turbocharger under a lean-burn condition. They also found that the thermal efficiency was increased and knocking was avoided when using HCNG with a high compression ratio and a delayed sparktime.

On the basis of the above results, in this study, we aimed to find an appropriate fuel for a rotary engine and investigated the supply and mixing ratio of air and fuels using the data from various sensors. The fuels tested were methane, methanol, and hydrogen. Methanol has been used for a rotary engine but not methane, whereas hydrogen still needs further study on its feasibility before it can be used as a fuel. In this study, advanced sensor technology contributed significantly to monitoring and processing the data from the engine using the different fuels, along with substitution and conversion processors. The data from the sensors and processors allowed stable combustion conditions to be found for different fuels. Our results provide basic information on appropriate fuels for rotary engines, enabling their adoption in more vehicles.

\section{Research Methods}

A 5 cc rotary engine (49-PI type II) was used in this study. Table 1 describes the specifications of the engine.

Three different fuels, methane, methanol, and hydrogen, were tested with the engine. Methanol has recently been used for rotary engines, and the intake conditions of hydrogen

Table 1

Specifications of 49-PI rotary engine.

\begin{tabular}{lc}
\hline Item & Specification \\
\hline Displacement & $4.97 \mathrm{cc}\left(0.303 \mathrm{in}^{3}\right)$ \\
Bore & - \\
Stroke & - \\
Practical speed & $2500-18000 \mathrm{RPM}$ \\
Power & $1.27 \mathrm{bhp} / 17000 \mathrm{RPM}$ \\
Weight & $335 \mathrm{~g}(11.8 \mathrm{oz})$ \\
\hline
\end{tabular}


and methane in a rotary engine are similar to those of methanol. The operating range, optimal output power, and torque using different fuels were analyzed using the data collected from the sensors in the rotary engine.

During the operation, the engine speed and the temperature of the exhaust air were measured by a tachometer and a temperature sensor. The torque was estimated from the force and the reaction force on the shaft measured by sensors. The computer software collected all of the measurement data. Figure 1 shows a diagram of the experiment in this study.

\section{Results and Discussion}

Kahraman et al. studied the performance and emission characteristics of hydrogen for a spark-ignition (SI) engine that combusted gasoline and hydrogen. ${ }^{(5)}$ The results showed serious power loss at low speeds, but the performance was better than that of a gasoline engine at the same high speeds. Their study suggested that because of the rapid combustion of hydrogen, the SI engine using hydrogen operated at high speeds with appropriate output power and efficiency. Bilge experimentally studied the performance and emission of a hydrogen-fueled SI engine (HFSIE), and proposed that an appropriate spark plug gap (SPG) was an important factor for engine performance. ${ }^{(6)}$ Considering the previous results, we carried out experiments to find the operation range, output power, output torque, and exhaust air temperature of the rotary engine with methane, methanol, and hydrogen.

Figure 2 shows the operating range of the rotary engine with methane, methanol, and hydrogen. The stable operating ranges were 7000-14000 RPM for methane, 5000-18000 RPM for methanol, and 6000-10000 RPM for hydrogen. When the engine speed was below 6000 RPM, starting the engine with hydrogen and methane was difficult. Above 10000 RPM, the engine with hydrogen did not have stable operation due to vibration and overheating. The 1000-fold volume increase of methanol from liquid to gas in the combustion chamber contributed to its wider range of the engine speed with stable combustion. Although the amount of air inflow increased at an engine speed of over 15000 RPM, the rotational inertia increased owing to the flywheel effect, causing the air intake to decrease.

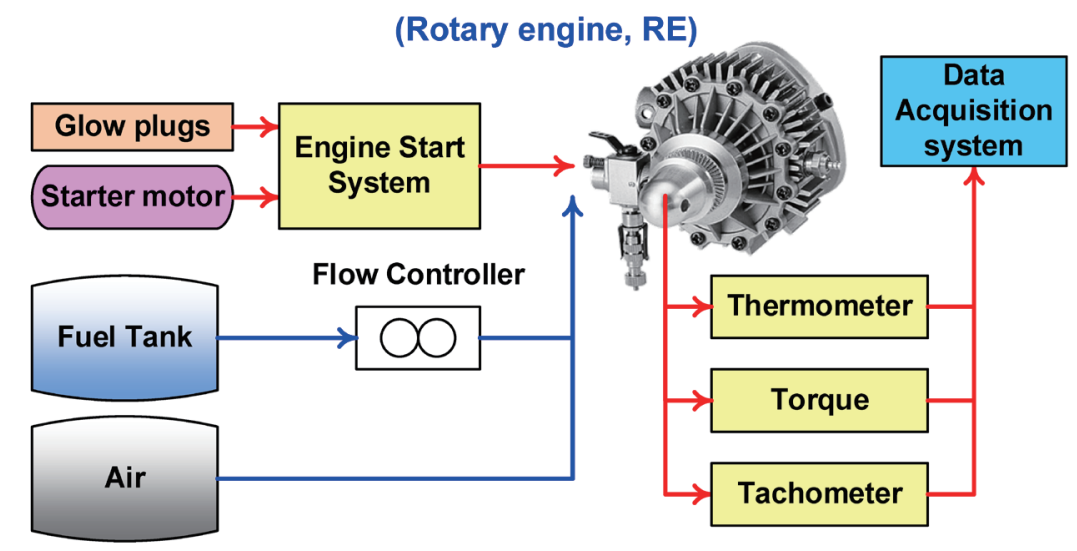

Fig. 1. (Color online) Schematic diagram of the experiment. 


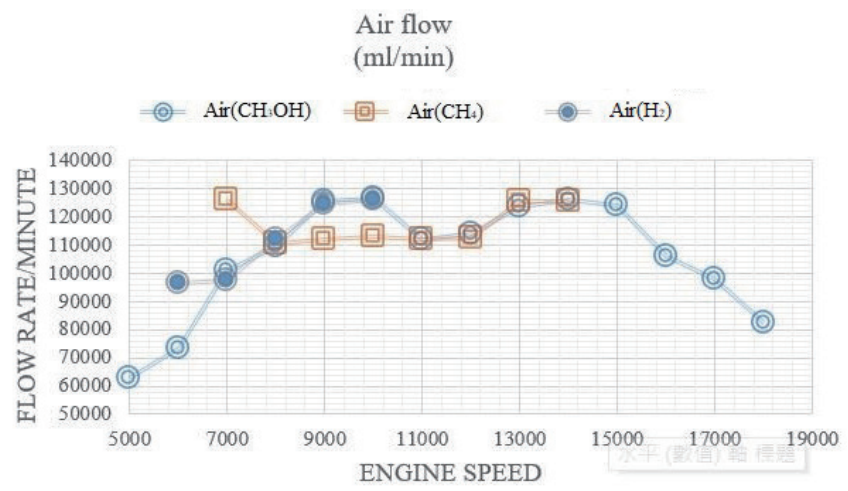

Fig. 2. (Color online) Comparison of the operating range of the three fuels for the rotary engine.

Figure 3 shows a comparison of the output powers using methane, methanol, and hydrogen. The output power of the rotary engine increased with the engine speed. The output powers for the three fuels were similar within their operating ranges. At the same RPM, the powers for methane and hydrogen were higher than that for methanol. Figure 4 shows a comparison of the output torque using the three fuels. At the same RPM, the torque for methanol was lower than those for the other fuels. The output torque for hydrogen was higher than those of methanol and methane in the operating range of 6000-10000 RPM.

In general, the output power increased with the speed of the rotary engine. However, the output torque of the rotary engine was different from that of a piston engine, whose output torque is highest at a low speed. The engine using methane showed the highest exhaust temperature among the fuels (Fig. 5). According to the combustion design of the rotary engine, its compression ratio (15-17:1) was much less than that (14-25:1) of a diesel engine. In general, the pre-ignition time, pressure, and threshold temperature with gas fuels are shorter and lower than those with a liquid fuel as the mixing effect of a gas fuel is faster. That is, the pre-ignition condition of methane and hydrogen was more appropriate than that of methanol for the rotary engine.

The exhaust air temperature using methane was higher than those using methanol and hydrogen due to poor lubrication. The exhaust air temperature using methanol was similar to that of hydrogen at a speed lower than $9000 \mathrm{RPM}$. The temperature ranges of the exhaust air were 200 to $480{ }^{\circ} \mathrm{C}$ with methane, 100 to $430{ }^{\circ} \mathrm{C}$ with methanol, and 100 to $200{ }^{\circ} \mathrm{C}$ with hydrogen. However, when the speed increased, the temperature increased for methane and methanol. The temperature of the exhaust air for hydrogen increased to $200{ }^{\circ} \mathrm{C}$, then became stable when the engine speed increased. A continuous increase in the temperature occurred when using methane and methanol as their volume increased in the combustion chamber. Slow mixing caused a delayed effect and widened the range of combustible temperatures of methane and methanol. Because of the difficulty of cooling for complete combustion, the rotary engine using hydrogen did not operate stably at high speeds. This caused the low exhaust air temperature even at high engine speeds. 


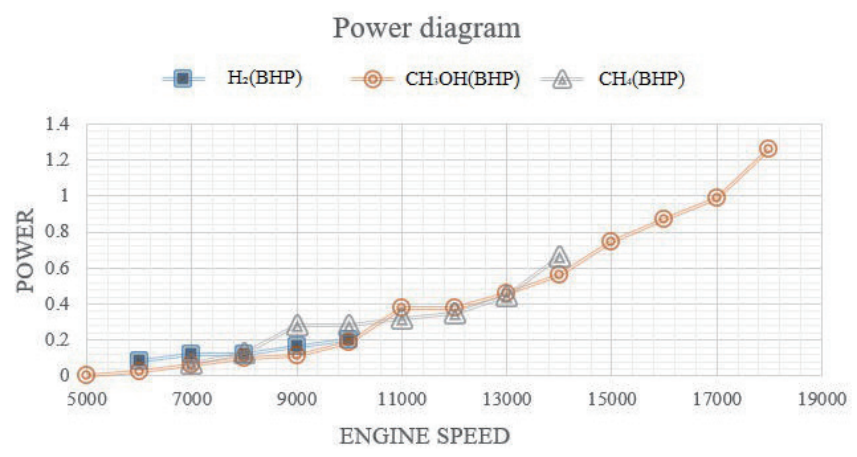

Fig. 3. (Color online) Comparison of output power for the three fuels.

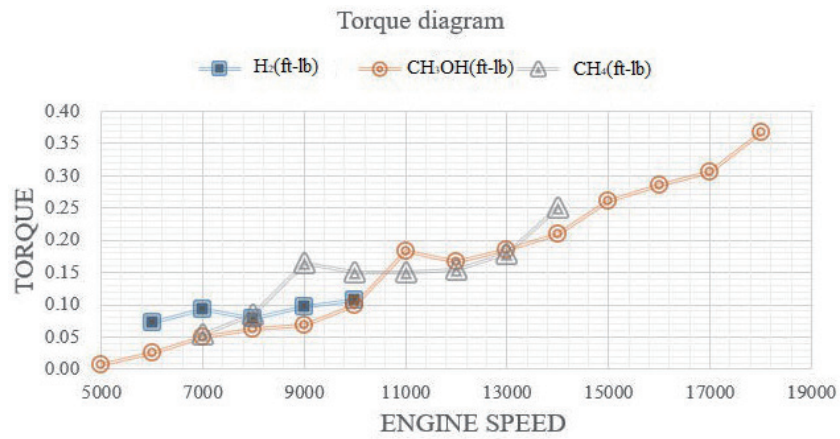

Fig. 4. (Color online) Comparison of output torque for the three fuels.

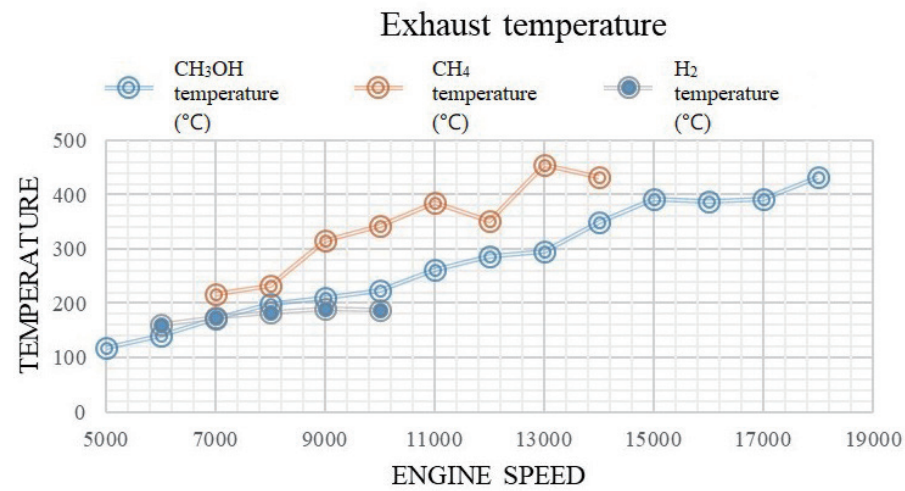

Fig. 5. (Color online) Comparison of the exhaust air temperatures for the three fuels.

\section{Conclusions}

Methane, methanol, and hydrogen were tested for use in a rotary engine in terms of speed, output power, output torque, and exhaust air temperature. Methane used in a rotary engine had the advantage on operation at relatively the same engine speed. At low speeds, the output torque using hydrogen was higher than those using the other fuels. The rotary engine operated stably 
from 7000 to 14000 RPM using methane, from 5000 to 18000 RPM using methanol, and from 6000 to 10000 RPM using hydrogen. The results showed that using methanol for the rotary engine yielded better efficiency than that using methane and higher output power and torque than those using hydrogen. However, to use methanol for a rotary engine, a higher-pressure pump is recommended to expand the range of stable combustion. The poor lubrication and the resulting high temperature when using methane and hydrogen must be considered for their use in a rotary engine. The results of this study suggest the possibility of using fuels other than gasoline and diesel for the rotary engine, which should encourage further detailed research on each fuel.

\section{References}

1 Y. Zhenzhong, W. Jianqin, F. Zhuoyi, and L. Jinding: Hydrogen Energy J. 27 (2002) 213. https://doi. org/10.1016/S0360-3199(01)00096-9

2 C. Sopena, P. M. Dieguez, D. Sainz, J. C. Urroz, E. Guelbenzu, and L. M. Gandıa: Hydrogen Energy J. 35 (2010) 1420. https://doi.org/10.1016/j.ijhydene.2009.11.090

3 C. Park, S. Lee, G. Lim, Y. Choi, and C. Kim: Hydrogen Energy J. 38 (2013) 4809. https://doi.org/10.1016/ j.ijhydene.2013.01.079

4 C. Park, C. Kim, and Y. Choi: Hydrogen Energy J. 37 (2012) 8681. https://doi.org/10.1016/j.ijhydene.2012.02.052

5 E. Kahraman, S. C. Ozcanli, and B.Ozerdem: Int. J. Hydrogen Energy 32 (2007) 2066. https://doi.org/10.1016/ j.ijhydene.2006.08.023

6 A. C. Bilge: Int. J. Hydrogen Energy 37 (2012) 17310. https://doi.org/10.1016/j.ijhydene.2012.08.070 